\title{
Geociências
}

\section{Implicações geomorfológicas e paleogeográficas das crostas fosfáticas do Arquipélago de São Pedro e São Paulo, Atlântico Norte}

\author{
(Geomorphological and paleogeographical implications of the \\ phosphatized crusts in the São Pedro and São Paulo Archipelago, \\ North Atlantic)
}

\section{Fábio Soares de Oliveira \\ Professor do Instituto Federal Minas Gerais - Campus Ouro Preto Doutorando em Geologia Ambiental Departamento de Geologia Universidade Federal de Ouro Preto (DEGEO/UFOP), Ouro Preto, Brasil E-mail:fabio_solos@yahoo.com.br}

\section{Walter Antônio Pereira} Abrahão

Doutor em Solos, Professor Adjunto Departamento de Solos, Universidade Federal de Viçosa (DPS/UFV), Viçosa, Brasil E-mail:wabrahao@ufv.br

\section{Carlos Ernesto Gonçalves} Reynaud Schaefer

Ph.D. em Solos, Professor Associado Departamento de Solos, Universidade Federal de Viçosa (DPS/UFV), Viçosa, Brasil E-mail: carlos.schaefer@ufv.br

Felipe Nogueira Bello Simas

Doutor em Solos Bolsista de Pós Doutorado Departamento de Solos, Universidade Federal de Viçosa (DPS/UFV) Viçosa, Brasil E-mail:fsimass@yahoo.com.br

\section{Resumo}

No Arquipélago de São Pedro e São Paulo, a deposição de excrementos da avifauna foi responsável pela fosfatização de suas rochas. Como feição mais característica, formaram-se crostas fosfáticas. Com base em metodologias pertinentes ao trabalho de campo (observação, descrição e coleta) e de laboratório (análises geoquímicas, mineralógicas e microscópicas), esse trabalho buscou caracterizar tais crostas e compreender suas implicações geomorfológicas e paleogeográficas. As crostas foram definidas como feições de acumulação de excrementos, ricos em fósforo, mineralizados sobre rochas homogêneas (peridotitos milonitizados). Depois de formadas, o comportamento hidrofóbico de tais crostas protegeu as rochas contra o avanço acelerado do perfil de alteração e da atuação de processos erosivos, tornando as encostas em que são encontradas mais íngremes e convexizadas. Ao contrário, onde a formação da crosta não foi verificada, as encostas encontram-se concavizadas e a rocha mais profundamente alterada. A presença de tais crostas também indica a existência de ambientes áridos pretéritos, diferentes das condições climáticas atuais, onde foi possível a acumulação do guano sobre a superfície.

Palavras-chave: Fosfatização, crostas fosfáticas, implicações geomorfológicas, Arquipélago de São Pedro e São Paulo.

\begin{abstract}
In the São Pedro and São Paulo Archipelago, deposition of bird excrements has been responsible for rock phosphatization, generating phosphatized crusts. This study describes these crusts and establishes their geomorphological and paleogeografical implications, based on methodologies such as field observation, description and sampling, as well as, laboratorial analyses (geochemical, mineralogical and microscopic). The crusts were defined as features of excrement accumulation, with high $P$ content and mineralized surfaces over homogeneous rocks (milonitizaded peridotites). The hydrophobic behavior of these crusts protects the underlying rock against the accelerated advance of chemical weathering and, consequently, the role of erosion processes, developing steeper and more convex slopes. In contrast, at sites in which the formation of the crust has not been verified, the rock is more weathered and the slopes more concave. The presence of these
\end{abstract}


Implicações geomorfológicas e paleogeográficas das crostas fosfáticas do Arquipélago de São Pedro e São Paulo...

crusts also indicates an arid paleoenvironment, where guano accumulation was possible, differently from presentday climate conditions.

Keywords: Phosphatization, phosphatized crusts, geomorphological implications, São Pedro and São Paulo Archipelago.

\section{Introdução}

Localizado em águas brasileiras, distante cerca de $1.010 \mathrm{~km}$ do Cabo do Calcanhar (RN), o Arquipélago de São Pedro e São Paulo (ASPSP) é o único arquipélago do país no Hemisfério Norte (Figura 1), sendo constituído por um pequeno grupo de ilhas (10) e diversas saliências rochosas que se situam nas proximidades da Dorsal Meso-Atlântica, com área total de 1,7 ha (Figura 2).

Além de possuir uma geologia singular, sendo constituído por peridotitos milonitizados e serpentinizados, bem como por uma formação sedimentar de caráter biolitoclástico (Campos et al., 2003), o ASPSP possui grande parte de sua área emersa recoberta por excrementos de aves que ali constrõem seus ninhais, tornando-se palco do processo de fosfatização. A primeira referência a esse processo em tais ilhas foi feita por Charles Darwin, em 1844.
Conceituada como um processo específico de formação de solos, a fosfatização representa uma interação entre substrato e excrementos, ricos em fósforo, de animais (Simas et al., 2007), possuindo estreita relação com o retorno do fósforo, via lixiviação e/ou erosão, ao mar (Schaefer et al., 2004) e, por conseqüência, com a produtividade primária das áreas marinhas adjacentes.

A partir disso, considerando a existência de rochas fosfatizadas no ASPSP, esse trabalho teve como objetivo caracterizar e avaliar as implicações geomorfológicas e paleogeográficas das crostas fosfáticas formadas sobre os peridotitos do Arquipélago de São Pedro e São Paulo, reconhecendo sua influência na evolução do modelado da área de estudo.

\section{Materiais e métodos}

Foram estudadas duas encostas na principal ilha do Arquipélago, denominada Ilha Belmonte (Figura 2): a encosta oeste recoberta pelas crostas e a encosta leste, onde as mesmas não são identificadas. Em ambas foram coletadas amostras de rochas (crostas fosfáticas separadamente - R1; amostras da encosta oeste - R2 e amostras da encosta leste - R3), sendo, então, preparadas e submetidas a análises. O preparo das amostras envolveu sua fragmentação em seções, isto é, camadas representativas dos diferentes níveis de interação do substrato com o excremento depositado sobre ele (Tabela 1). Em seguida, as amostras foram moídas em almofariz de ágata e passadas por peneiras de 200 mesh (0,074 mm).

A análise dos teores totais dos elementos $\mathrm{Cr}, \mathrm{Cu}, \mathrm{Ni}, \mathrm{Pb}$ e $\mathrm{Zn}$ foi feita através do ataque tri-ácido $\left(\mathrm{HNO}_{3}, \mathrm{HCl}\right.$ e HF) em microondas (Modelo CEM 2000), a 100 psi por $20 \mathrm{~min}$ a $650 \mathrm{~W}$. A digestão inorgânica foi promovida com $2 \mathrm{~mL}$ de $\mathrm{HCl}, 9 \mathrm{ml}$ de $\mathrm{HNO}_{3}$ e 4 $\mathrm{ml}$ de $\mathrm{HF}$ adicionado a $0,3 \mathrm{~g}$ de material, com posterior determinação dos teores dos elementos por espectrofotometria de emissão em plasma induzido (ICPOES). Os elementos P, Na, K, Fe, Al, Ca, Si e Mg foram determinados por fusão alcalina com 0,24 g de $\mathrm{LiBO}_{2}$ e 0,05 g de amostra em cadinhos de grafite de alta pureza, a uma temperatura (mufla) de $1.000^{\circ} \mathrm{C}$, e posterior diluição da pastilha fundida, aí formada, com $\mathrm{HNO}_{3}$. A determinação dos teores também foi feita por ICP-OES.

A mineralogia foi obtida por Difratometria de Raios X em difratômetro modelo Rigaku, radiação de CoK . A interpretação dos difratogramas teve como referência os trabalhos desenvolvidos por Brindley e Brown (1980), Nriagu e Moore (1984) e Simas (2006). As amostras foram também submetidas à observação em Microscópio Eletrônico de Varredura (MEV) e posterior espectrometria obtida por EDS. Seções finas, previamente estudadas em microscópio

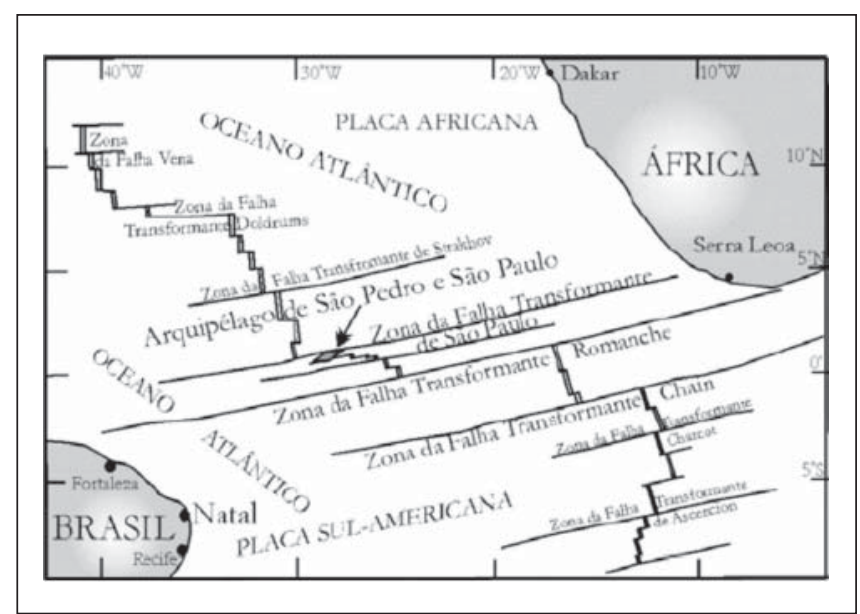

Figura 1 - Localização do ASPSP. Fonte: Campos et al. (2005).

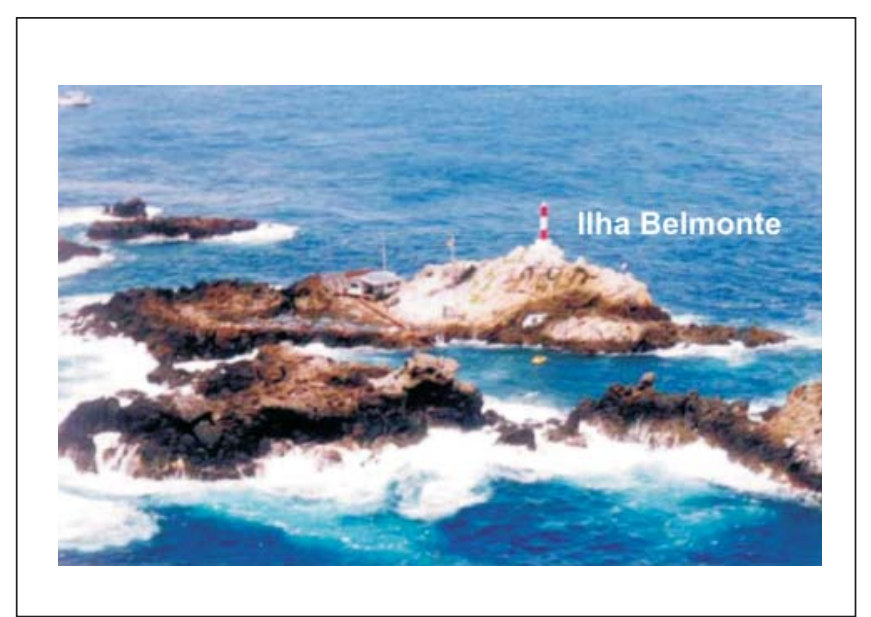

Figura 2 - Vista panorâmica do ASPSP. Fonte: Campos et al. (2005). 
petrográfico, foram preparadas para microanálise em microscopia eletrônica de varredura, modelo JEOL JSM 6400, com detector backscattering e acoplado a espectrômetro de dispersão de raios $\mathrm{X}$ (PCXA - EDS). A partir de um menu dos principais elementos (Si. Ca, Mg, P, Fe, $\mathrm{K}, \mathrm{Cu}, \mathrm{Ni}, \mathrm{Co}, \mathrm{Al}$, entre outros), foram produzidos mapas microquímicos das áreas selecionadas. Tanto as análises geoquímicas quanto as análises mineralógicas foram realizadas nos laboratórios do Departamento de Solos da Universidade Federal de Viçosa.

\section{Resultados e discussão}

\subsection{Caracterização das crostas fosfáticas}

Ao analisar a distribuição da cobertura das rochas por crostas fosfáticas espessas, observa-se que elas se restringem à face oeste da elevação do morro do farol, na Ilha Belmonte (Figura 2). Observações de campo permitem inferir que tais crostas estão associadas ao peridotito milonitizado sem serpentinização. Darwin (1844), ao observá-las, descrevera-as como sendo formadas "por finas lamelas de fosfatos cuja efervescência, mediante ataque ácido (experimentos realizados por ele em campo), não foi reconhecida”. Possuía, segundo o naturalista, espessura próxima de 2,5 mm (um décimo de polegada). Os relatos são confirmados pelas observações atuais.

Análises químicas do material coletado (somente a crosta - Amostra R1) apresentaram altos teores de $\mathrm{CaO}$ $(45,73 \%)$ e $\mathrm{P}_{2} \mathrm{O}_{5}(31,42 \%)$, associados a teores mais baixos, porém significativos, de $\mathrm{SiO}_{2}$ (16,93\%), $\mathrm{MgO}$ (2,73\%) e $\mathrm{Fe}_{2} \mathrm{O}_{3}(1,13 \%)$. Teores de $\mathrm{Al}_{2} \mathrm{O}_{3}, \mathrm{ZnO}$, CuO. NiO e $\mathrm{Cr}_{2} \mathrm{O}_{3}$ aparecem com baixos valores (Tabela 2). Proporções semelhantes foram encontradas por Renard (1882), citado por Hutchinson (1950), para o mesmo material (50\% de $\mathrm{CaO}$ e 33,61\% de $\mathrm{P}_{2} \mathrm{O}_{5}$ ).

A análise mineralógica da crosta aponta para uma associação entre apatita, piroxênio e olivina (Figura 3). Existem fragmentos do manto de degradação da rocha subjacente, que, provavelmente, misturam-se ao excremento depositado, respondendo pelos picos de minerais ferromagnesianos encontrados na crosta. Juntos, representam uma assembléia de minerais ultramáficos envolvidos pela massa fosfática. É provável que parte da apatita presente na crosta não seja neoformada, pois alguns picos podem ser apatitas biogênicas que resistiram ao trato digestivo dos animas e foram eliminadas junto com seus excrementos.
Os estudos da amostra R2, um peridotito milonitizado coberto pela crosta fosfática, revelaram um contraste bastante acentuado entre as seções (R2.1 - crosta, R2.2 - manto de intemperismo superior e R2.3 - rocha). Do ponto de vista geoquímico, numa comparação com o material subjacente, a crosta se confirma como uma acumulação de $\mathrm{P}$ e Ca (Tabela 2), ocorrendo diminuição desses elementos no sentido crosta $\rightarrow$ rocha. Ficam como heranças de sua interação com o manto de intemperismo superficial da rocha os altos teores de magnésio e ferro. Elementos como níquel e cromo permanecem como traço na crosta, aumentando no interior do substrato (Tabela 2), típico de uma assinatura geoquímica ultramáfica.

Os aspectos mineralógicos característicos da cobertura das rochas pela crosta se confirmam no contraste entre as três seções da amostra R2 (Figura 4). De 1 para 3, observam-se reduções na intensidade e/ou ocorrência dos picos da apatita associado ao aumento e/ou permanência da intensidade dos picos dos minerais ferromagnesianos.

As análises das amostras R1 e R2 evidenciam estreita relação entre a composição química dessa crosta e os elementos constituintes dos dejetos animais, haja vista que a rocha subjacente

Tabela 1 - Descrição das amostras coletadas no Arquipélago de São Pedro e São Paulo.

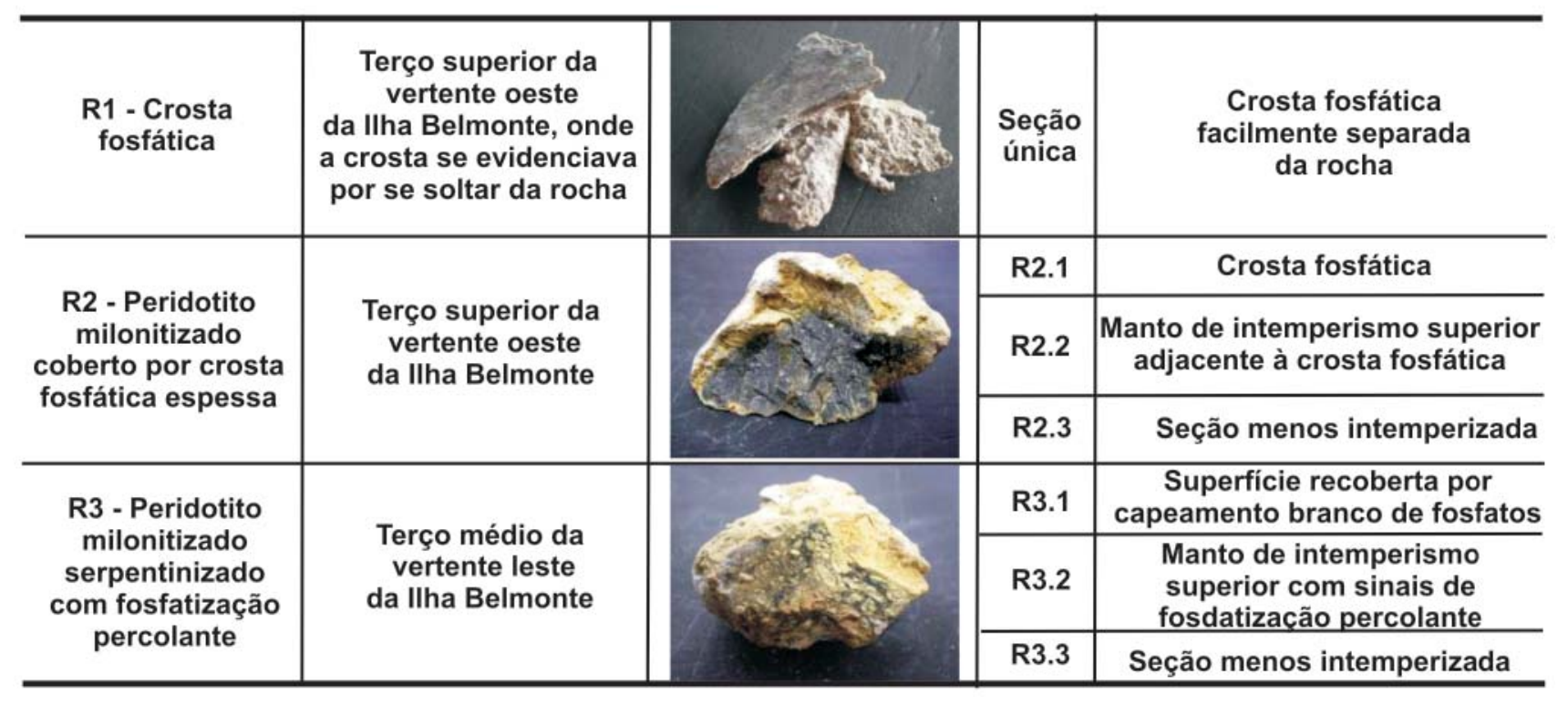


Implicações geomorfológicas e paleogeográficas das crostas fosfáticas do Arquipélago de São Pedro e São Paulo...

contém pouco cálcio e fósforo (Green, 1964). Em contrapartida, a dieta das aves que habitam o ASPSP é constituída, principalmente, de sete a nove espécies de peixes, destacando-se a família Exoetidae responsável por cerca de 93\% das presas consumidas, em que tais elementos são abundantes (Both \& Freitas, 2001). Esse contraste fica evidenciado pelos mapas microquímicos elaborados na interface entre a crosta e o peridotito (Figura 5). Tais mapas contrastam um substrato ferromagnesiano fosfatizado em superfície, sem que se observe, entretanto, percolação dos fosfatos na estrutura da rocha. Por ser menos fraturado, os excrementos parecem se acumular sobre o peridotito milonitizado sem serpentinização, formando a crosta.

Nas amostras em que não fora reconhecida a presença de crostas fosfáticas (R3), observou-se um intenso fraturamento (macro e micro) característico dos peridotitos milonitizados e serpentinizados. Tais fraturas atuam no intemperismo mais avançado de tais rochas e como dutos da percolação dos excrementos depositados, evitando que os mesmos se acumulem na superfície.
Por conseqüência, há uma interação geoquímica entre a solução rica em $\mathrm{P}$ e o saprolito da rocha, culminando na neoformação de minerais fosfáticos sem que se observe a formação da crosta.
O saprolito dos milonitos de peridotitos serpentinizados tem na sua composição química marcas dos intensos processos intempéricos pelos quais vem passando desde a exposição da

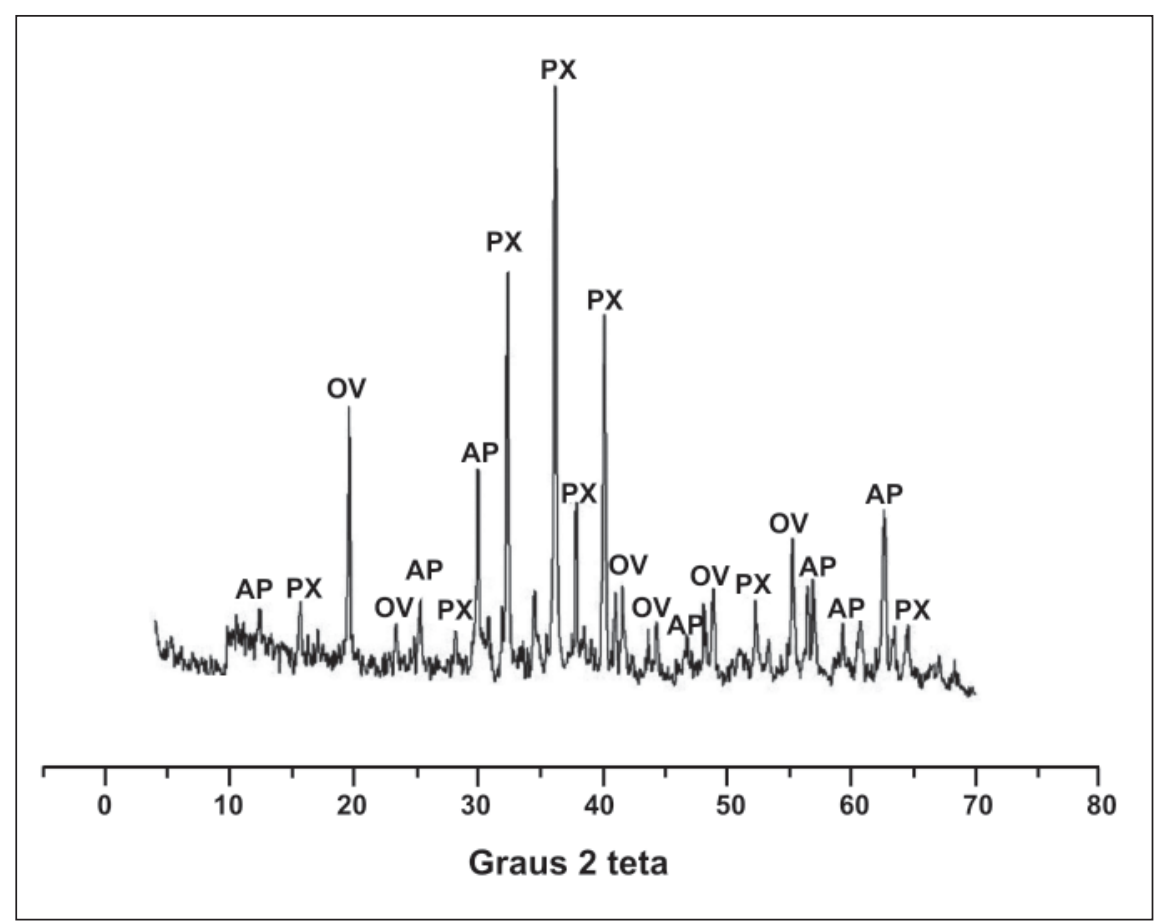

Figura 3 - Difratograma de Raios $X$ (radiação CoK ) da crosta fosfática sob peridotito milonitizado; Amostra R1, sendo AP - apatita; OV - olivina e PX - piroxênio.

Tabela 2 - Composição química expressa em \% em peso de óxidos das amostras do ASPSP.

\begin{tabular}{|c|c|c|c|c|c|c|c|c|c|c|c|c|c|c|}
\hline Seções & $\mathrm{SiO}_{2}$ & $\mathrm{Al}_{2} \mathrm{O}_{3}$ & $\mathrm{Fe}_{2} \mathrm{O}_{3}$ & MgO & $\mathrm{CaO}$ & $\mathrm{Na}_{2} \mathrm{O}$ & $\mathrm{K}_{2} \mathrm{O}$ & $\mathrm{P}_{2} \mathrm{O}_{5}$ & $\mathrm{Cr}_{2} \mathrm{O}_{3}$ & $\mathrm{PbO}$ & $\mathrm{ZnO}$ & $\mathrm{CuO}$ & $\mathrm{NiO}$ & Total \\
\hline \multicolumn{15}{|c|}{$\%$ em peso } \\
\hline \multicolumn{15}{|c|}{ R1 - Crosta Fosfática } \\
\hline Única & 16,93 & 0,40 & 1,13 & 2,73 & 45,73 & 1,42 & nd & 31,42 & 0,02 & nd & 0,06 & 0,02 & 0,01 & 99,87 \\
\hline \multicolumn{15}{|c|}{ R2 - Peridotito Milonitizado coberto por crosta fosfática espessa } \\
\hline 1 & 30,06 & 2,15 & 7,39 & 18,94 & 24,31 & 0,31 & 1,42 & 15,14 & 0,04 & nd & 0,02 & nd & 0,02 & 99,80 \\
\hline 2 & 46,47 & 1,32 & 6,10 & 34,10 & 5,88 & 0,24 & 1,16 & 1,37 & 0,36 & nd & 0,01 & nd & 0,22 & 97,23 \\
\hline 3 & 45,96 & 0,91 & 6,96 & 38,48 & 1,94 & 0,02 & 1,35 & nd & 0,34 & nd & nd & nd & 0,25 & 96,21 \\
\hline \multicolumn{15}{|c|}{ R3 - Peridotito Milonitizado Serpentinizado com fosfatização percolante } \\
\hline 1 & 53,69 & 1,89 & 6,67 & 24,26 & 1,34 & 0,67 & 1,03 & 9,58 & 0,20 & 0,04 & 0,02 & 0,02 & 0,13 & 99,54 \\
\hline 2 & 55,39 & 1,62 & 3,40 & 21,60 & 1,99 & 1,18 & 1,51 & 5,75 & 0,23 & 0,01 & 0,01 & 0,01 & 0,19 & 92,89 \\
\hline 3 & 41,37 & 2,06 & 9,86 & 32,83 & 2,79 & 3,84 & 1,31 & 2,92 & 1,31 & nd & nd & 0,01 & 0,26 & 98,56 \\
\hline
\end{tabular}

nd = não detectado. 
Fábio Soares de Oliveira et al.

rocha à atmosfera. Com a fosfatização, essa composição tende a se alterar ainda mais, sobretudo na área de interferência dos excrementos. Evidências geoquímicas apontam para altos teores de $\mathrm{P}_{2} \mathrm{O}_{5}$ na rocha também em profundidade. Observam-se, por exemplo, teores que correspondem a 9,58\% na Seção 01 da amostra R3 e 5,75\% na Seção 02 (Tabela 2). Se comparada com a Seção 2 das amostras R2, esses valores reduzem para $1,37 \%$ de $\mathrm{P}_{2} \mathrm{O}_{5}$. Outros elementos, cuja contribuição provém dos excrementos, possuem comportamento análogo, isto é, exibem em profundidade teores semelhantes ou maiores que na superfície, como é o caso do cálcio e do potássio (Tabela 2 - Amostra R3).

A mineralogia confirma tais observações (Figura 6), na medida em que é encontrada apatita também em profundidade, algumas vezes com picos de maior intensidade que na crosta superficial. Observam-se, também, como produtos da interação geoquímica com o saprolito, formas cristalinas de fosfatos de Fe, Al e K, tal como a taranakita, não observadas na crosta sob o peridotito sem serpentinização.

A análise por MEV da amostra R3 revelou distintas formas de fosfatização nas fraturas do peridotito serpentinizado. Correspondem a preenchimentos das fraturas por soluções ricas em fósforo, com progressiva fosfatização das bordas pela interação geoquímica com o saprolito. Nesse caso, o excremento exerce a pedogênese via mineralização da matéria orgânica nele contida. As fraturas preenchidas pelos excrementos servem de locus para essa mineralização, tendo como resultado a formação de fosfatos minerais secundários de $\mathrm{Fe}, \mathrm{Al}$ e K citados. A Figura 7 apresenta a existência de tal fosfatização percolante.

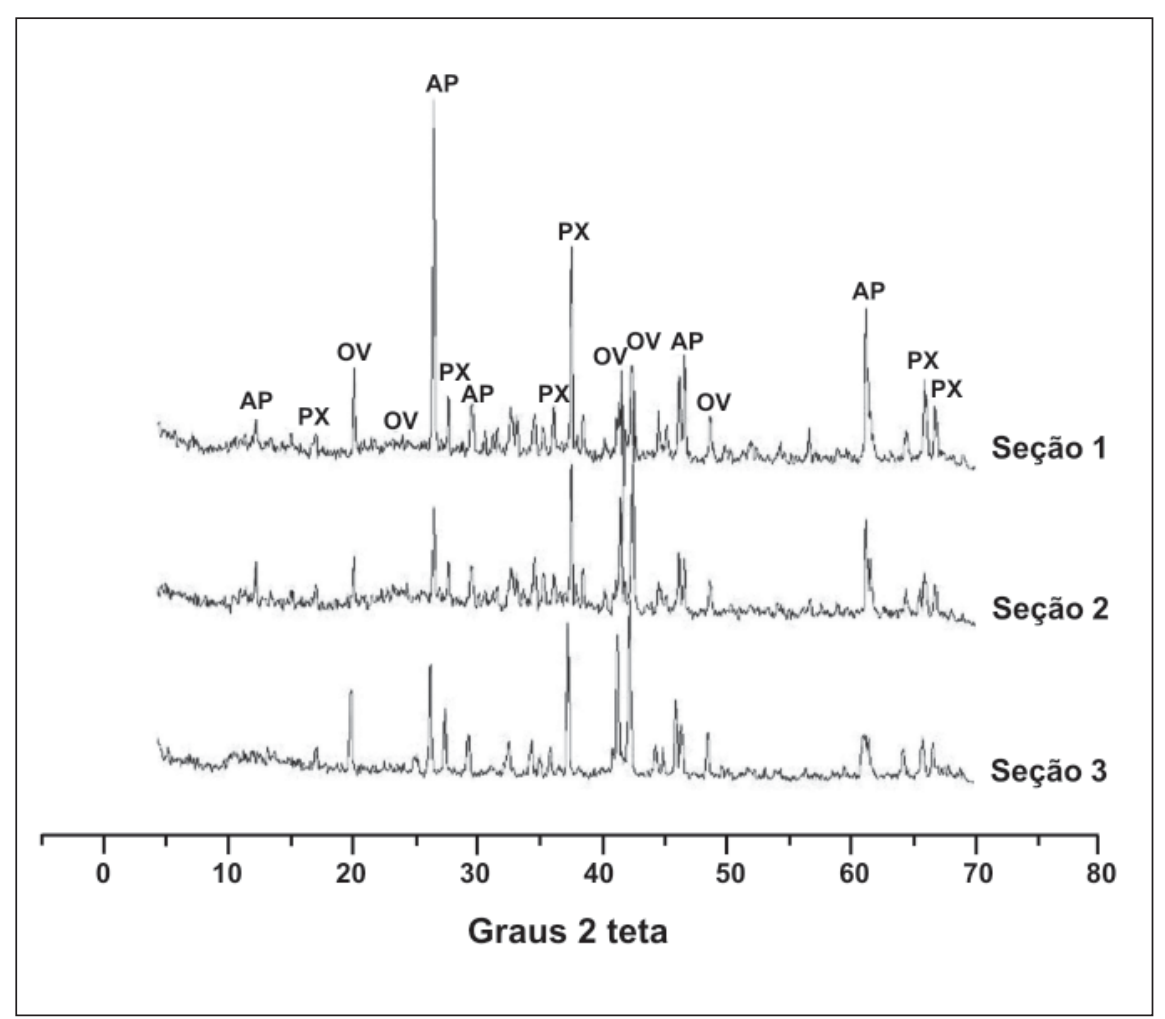

Figura 4 - Difratograma de Raios X (radiação CoK ) - Seção 1 (crosta fosfática), Seção 2 (manto de intemperismo superior, adjacente à crosta) e Seção 3 (rocha menos intemperizada) da amostra R2, sendo AP - apatita; OV - olivina e PX - piroxênio.

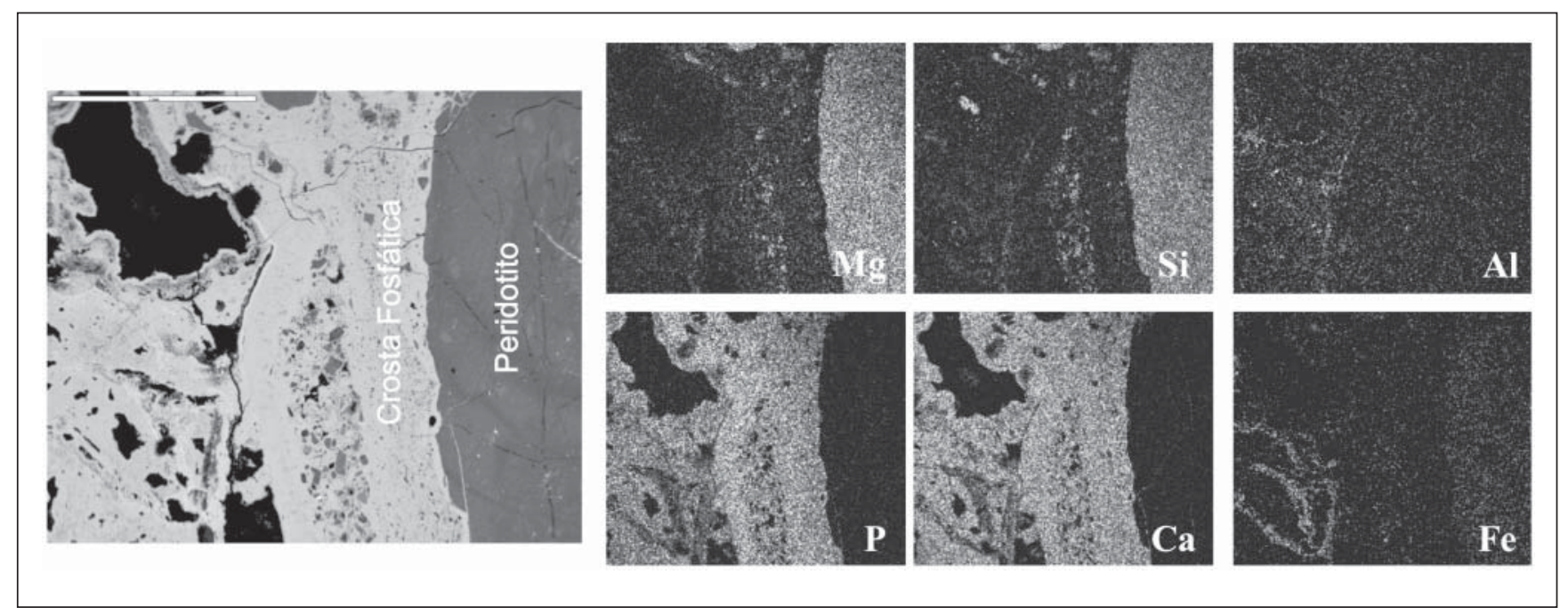

Figura 5 - Fotomicrografia em retroespalhamento eletrônico (MEV) e mapas microquímicos de EDS de crostas fosfáticas espessas sobre peridotito milonitizado (as feições mais claras indicam a distribuição e a quantidade relativa do elemento na lâmina analisada). 
Implicações geomorfológicas e paleogeográficas das crostas fosfáticas do Arquipélago de São Pedro e São Paulo...

\subsection{Crostas fosfáticas como indicador paleogeográfico}

É provável que algumas fases se sucedam no processo que leva à fosfatização das rochas do ASPSP, tornando as crostas fosfáticas indicadores paleogeográficos, isto é, a ocorrência do processo de fosfatização está subordinada à acumulação dos excrementos sobre o material a interagir com os mesmos. Por conseqüência, níveis avançados desse processo só ocorrerão em áreas cujas condições climáticas forem menos úmidas. Tal como Flicoteaux e Melfi (2005) expuseram para a formação de crostas fosfáticas nos saprolitos basálticos de Abrolhos, a fosfatização no ASPSP tem como característica sua intensificação em condições climáticas diferentes das atuais, haja vista que, por influência da Zona de Convergência Tropical, a região onde o Arquipélago se encontra é reconhecida na atualidade como uma das áreas de maior pluviosidade de todo Oceano Atlântico (Campos et al., 2005).

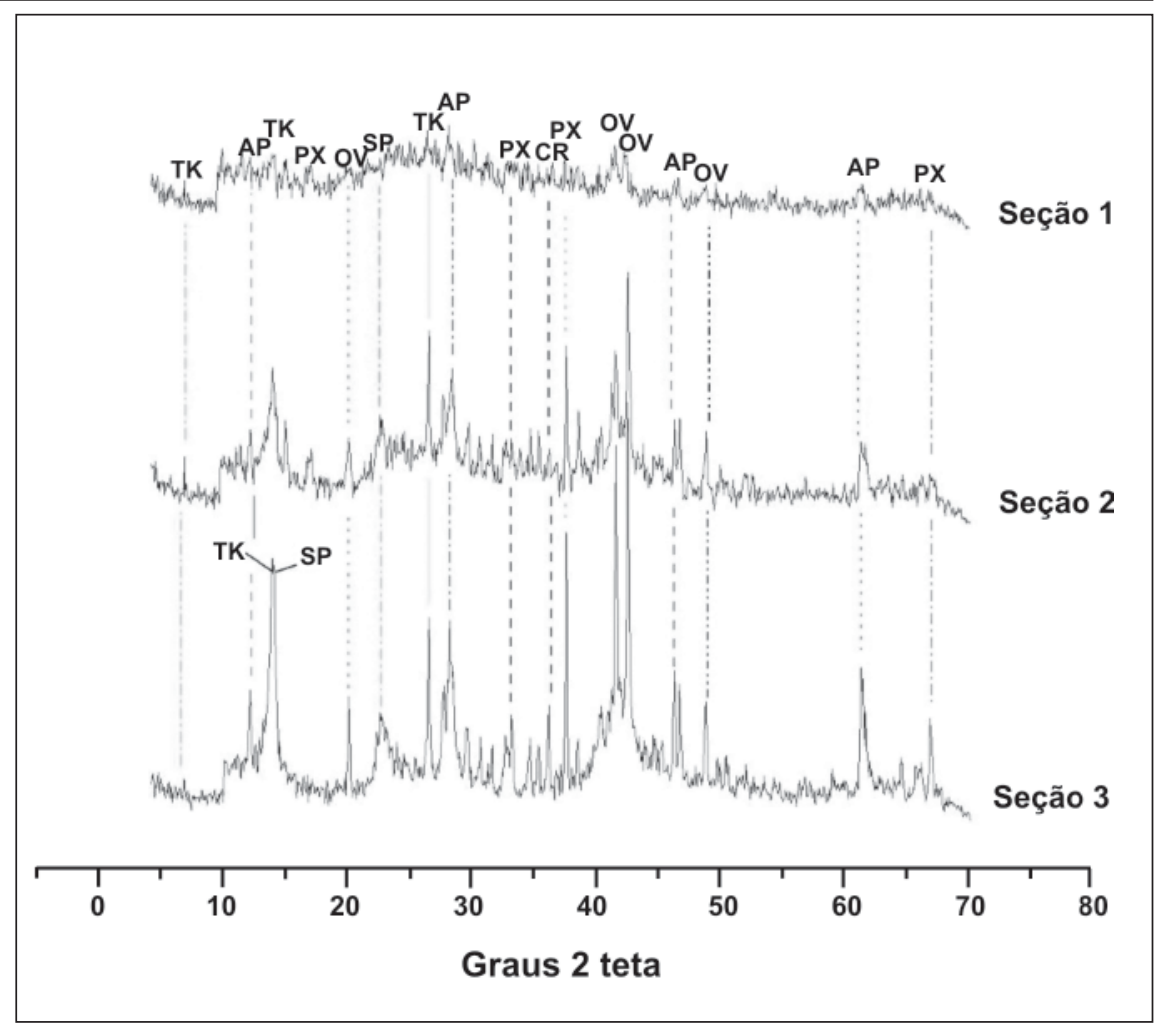

Figura 6 - Difratograma de Raios X (radiação CoK ) - Seção 1 (superfície recoberta por capeamento branco de fosfatos). Seção 2 (manto de intemperismo superior com sinais de fosfatização percolante). Seção 3 (rocha menos intemperizada) da amostra R3, sendo AP apatita; OV - olivina; PX - piroxênio; TK - taranakita; CR - cromita e SP - serpentina.

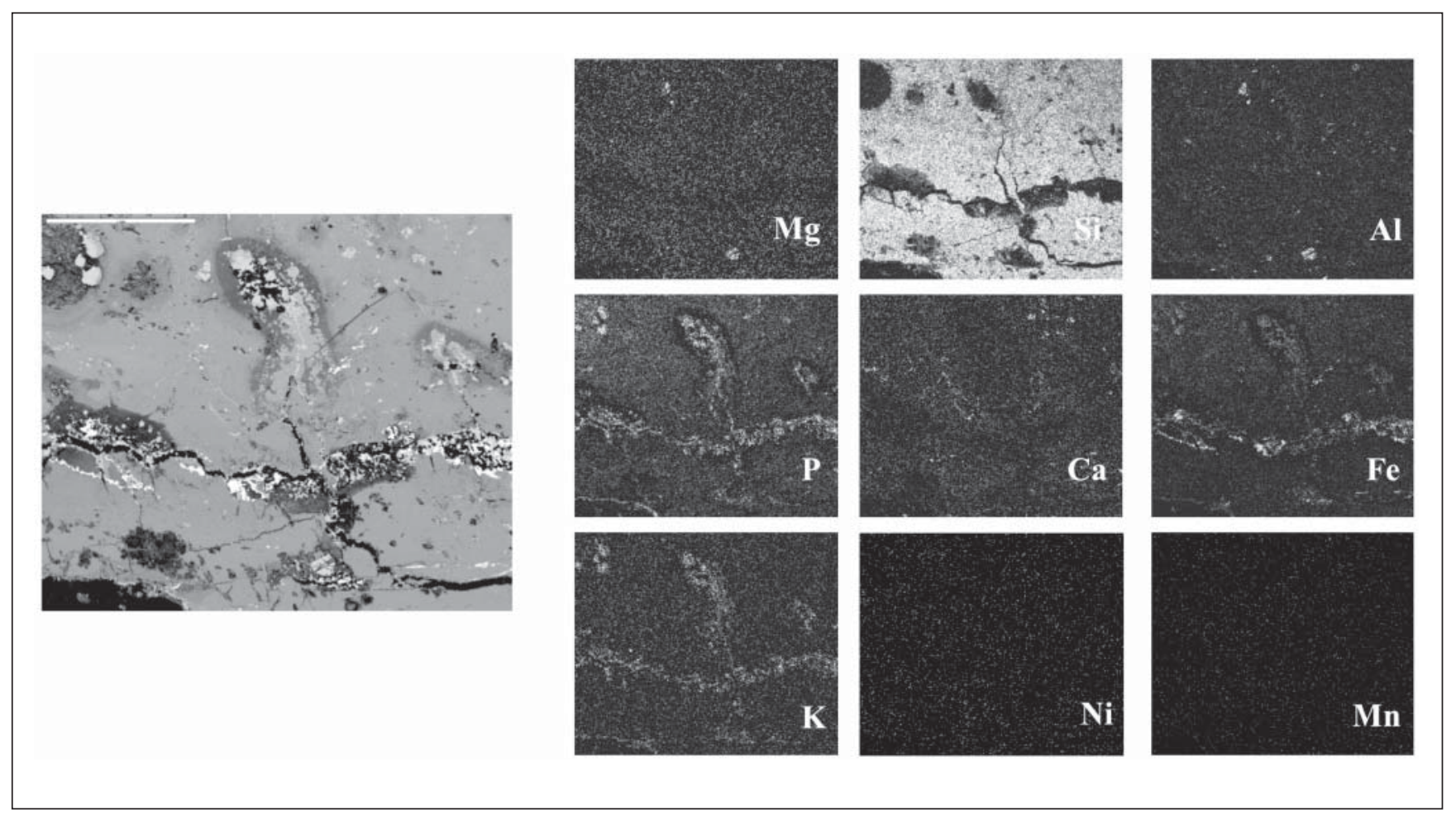

Figura 7 - Fotomicrografia em retroespalhamento eletrônico (MEV) e mapas microquímicos de EDS de material intemperizado de fraturas antigas, coletado a mais de $4 \mathrm{~m}$ de profundidade, correspondentes à amostra R3 (as feições mais claras indicam a distribuição e a quantidade relativa do elemento na lâmina analisada). 
Fábio Soares de Oliveira et al.

A partir do que se observa atualmente no ASPSP, podem ser reconhecidos três momentos distintos que levam à fosfatização de suas rochas: I - uma fase mais úmida, responsável pela formação de saprolitos identificados na maior parte da Ilha Belmonte, sobretudo a partir da alteração dos peridotitos milonitizados e serpentinizados; II - fosfatização das rochas pelo aumento do aporte de excrementos em condições climáticas áridas; III - condições úmidas atuais que se caracterizam pela destruição (lixiviação e erosão) dos produtos formados na fase anterior. É possível que essa fase tenha sido responsável pela erosão de possíveis perfis de solos formados no Arquipélago em condições pretéritas e também pela diminuição dos depósitos de guano.

\subsection{Crostas fosfáticas e o controle do intemperismo e da erosão}

Associações entre a evolução geomorfológica das encostas da Ilha Belmonte (faces leste e oeste) e a cobertura de suas rochas por crostas fosfáticas podem ser feitas a partir do estudo da distribuição da crosta e morfologia das encostas a elas associadas.

Como no período mais seco apenas parte das rochas (peridotitos milonitizados) foi revestida por crostas espessas e outra parte (peridotitos milonitizados serpentinizados) permitiu a percolação dos fluidos sem sua concentração na superfície, a atuação dos processos erosivos no momento atual, onde predomina a erosão dessas estruturas, processa-se de maneira diferenciada nessas encostas. Observa-se que, na área onde há o recobrimento pelas crostas, a vertente se apresenta com declividade mais acentuada, faces mais angulosas e perfil convexizado com caimento abrupto para o mar (Figura 8a). Em contrapartida, do outro lado, na face leste (Figura 8b), onde o saprolito ficava em exposição, a vertente é mais suavizada, descrevendo um perfil côncavo até se tornar íngreme na sua base, onde transiciona abrupta- mente para os costões rochosos. A exposição do saprolito nessa encosta faz com que ela esteja menos protegida dos processos erosivos.

\section{Conclusões}

1. Quando os fluidos ricos em P provenientes das excreções das aves são depositados sob rochas homogêneas e com baixo grau de fraturamento, ocorre uma acumulação superficial, cujo limite de percolação é o manto de intemperismo superior da rocha, quase sempre mais fragmentado que decomposto. Formam-se crostas cuja mineralogia é constituída por apatitas mais recalcitrantes, sejam elas neoformadas ou biogênicas. Quando a interação ocorre com rochas fraturadas, sendo essas intemperizadas e com caráter ferruginoso, a tendência é de que se formem novos minerais fosfáticos secundários, que preenchem essas fraturas, não havendo acumulação na superfície.

2. Em razão do seu comportamento hidrofóbico, as crostas fosfáticas protegem as rochas que recobrem o aprofundamento do manto de intemperismo nas condições úmidas atuais e da erosão. Por conseqüência, induzem à evolução de encostas mais estruturalizadas, íngremes e com perfis mais convexos, caindo abruptamente para o mar. Identificada sua inexistência, as encostas são mais côncavas e apresentam-se formadas por saprolitos de peridotitos expostos.

3. Por se tratar de um processo condicionado a climas mais secos, a fosfatização acentuada das rochas do ASPSP comporta-se como um excelente indicador paleoclimático de que condições mais áridas já afetaram a pedogênese naquele local, conprovando que as condições úmidas atuais são responsáveis pela erosão dos paleo-produtos da fosfatização.

\section{Referências bibliográficas}

BOTH, R., FREITAS, T. R. O. A dieta da Sula leucogaster, Anous stolidus e Anous minutus no Arquipélago de São Pedro e São Paulo, Brasil. In: ALBUQUERQUE, J. B., CANDIDO JUNIOR, F. C., ROSS, A. L. (Ed.). Ornitologia e conservação: da ciência às estratégias. Tubarão: Ed. Unisul, 2001. p. 313-337.

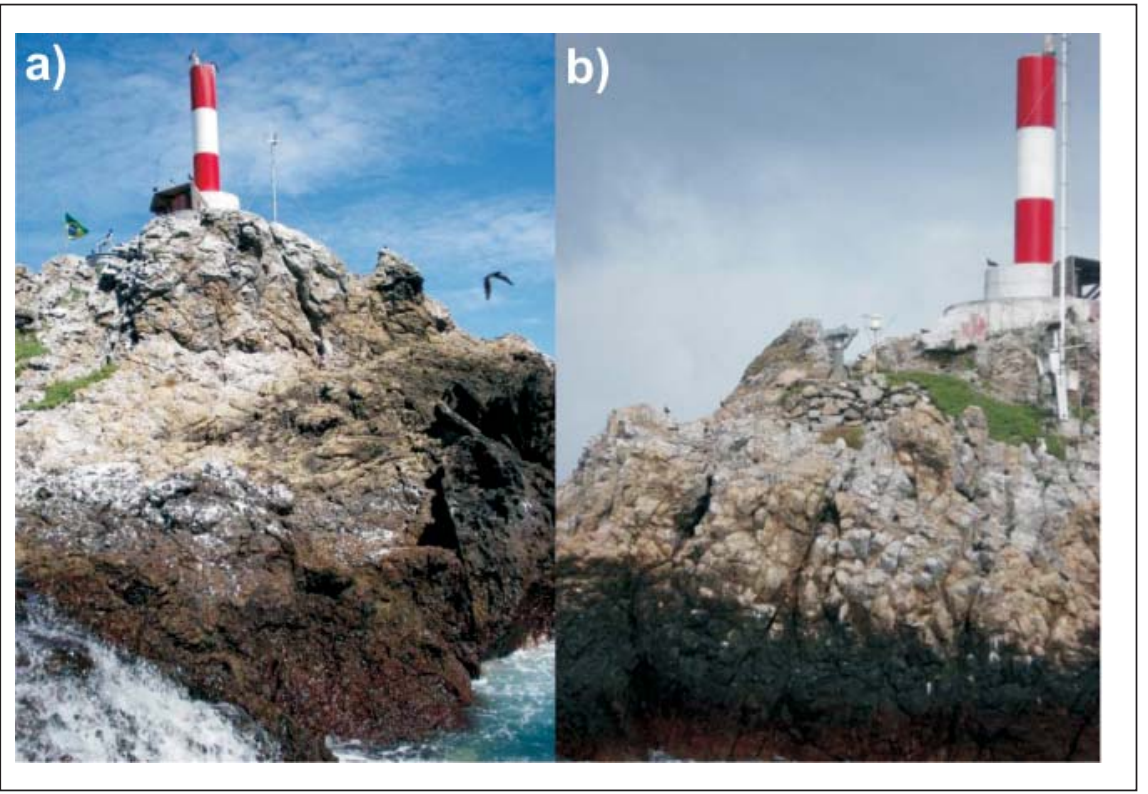

Figura 8 - a) Vertente leste, mais suave e concavizada, saprolito exposto à erosão. b) Vertente oeste, mais íngreme e com rochas cobertas por crostas e verniz. 
Implicações geomorfológicas e paleogeográficas das crostas fosfáticas do Arquipélago de São Pedro e São Paulo...

BRINDLEY, G.W. \& BROWN, G. Crystal structures of clay minerals and their $X$-ray identification. London: Mineralogical Society, 1980. $495 \mathrm{p}$.

CAMPOS, T. F. da C., VIRGENS NETO, J., SRIVASTARA, N. K., PETTA, R. A., HARTMANN, L. A., MORAES, J. F. S., MENDES, L., SUSAN, R. M. Arquipélago de São Pedro e São Paulo: soerguimento de rochas infracrustais no Oceano Atlântico. In: WINGE, M., SCHOBBENHAUS, C., BERBERTBORN, M., QUEIROZ, E.T., CAMPOS, D.A., SOUZA, C.R.G., FERNANDES, A.C.S. (Ed). Sítios geológicos e paleontológicos do Brasil. 2005. Disponível em http://www.unb.br/ig/sigep/ sitio002/sitio002.pdf. Acesso em 15 fev. 2008.

CAMPOS, T. F. C., SRIVASTAVA, N. K., MACAMBIRA, M. J. B PETTA, R.A., AMARAL, R., DAS VIRGENS NETO, J. A Formação São Pedro e São Paulo: uma nova unidade litoestratigráfica quaternária do Atlântico Equatorial Brasileiro. In: CONGRESSO BRASILEIRO DE GEOLOGIA, 151, 2003. Anais... João Pessoa: SBG, 2003, p. 353. (CD-ROM).

DARWIN. C. S. Geological observations on the volcanic islands, visited during the voyage of HMS Beagle, together with some brief notices on the geology of Australia and the Cape of Good Hope. London: Smith, Elder and Co., 1844. 175p.

FLICOTEAUX, R.; MELFI, A. Les croûtes phosphates des basalts de I'archipel d'Abrolhos (Bahia, Brésil): dês roches formées au Quaternaire récent à partir de guanos. Earth and Planetary Sciences, v. 330, 2005. p. 193-200.
GREEN, D. H. The petrogenesis of the hight-temperature peridotite inclusion in the Lizard area Cornwall. Journal of Petrology, Oxford, v. 5, 1964. p. 134-188.

HUTCHINSON, G. E. The biogeochemistry of vertebrate excretion. Bulletin of the American Museum of Natural History, New York, v. 96, 1950. 554 p.

NRIAGU, J.O., MOORE, P.B. Phosphate minerals. Berlim: Springer-Verlag, 1984. 442 p.

SCHAEFER, C. E. G. R., SIMAS, F. N. B., ALBUQUERQUEFILHO, M. R., MICHEL, R. F. M., VIANA, J., TATUR, H. M. Fosfatização: processo de formação de solos na Baía do Almirantado e implicações ambientais. In: SCHAEFER, C. E. G. R., FRANCELINO, R., SIMAS, F. N. B., ALBUQUERQUE FILHO, R. (Ed.). Ecossistemas costeiros e monitoramento ambiental da Antártica Marítima, Baía do Almirantado, Ilha Rei George. Viçosa: NEPUT-Departamento de Solos, 2004. p. 47-59.

SIMAS, F. N. B., SCHAEFER, C. E. G. R., MELO, V. F., ALBUQUERQUE-FILHO, M. R., MICHEL, R. F. M., PEREIRA, V. V., GOMES, M. R. M., DA COSTA, L. M. Ornithogenic cryosols from Maritime Antarctica: Phosphatization as a soil forming process. Geoderma, Amsterdan, v. 138, n. 3-4, 2007. p. 191-203.

SIMAS, F. B. Solos da Baía do Almirantado, Antártica Marítima: mineralogia, gênese, classificação e biogeoquimica. Viçosa: Departamento de Solos, Universidade Federal de Viçosa, 2006. 153 p . (Tese de Doutorado em Solos e Nutrição de Plantas).

Artigo recebido em 09/09/2009 e aprovado em 01/02/2010.

\section{A REM tem novo endereço:}

\section{FUNDAÇÃO GORCEIX - REM}

Rua Carlos Walter Marinho Campos, 57 Bairro: Vila Itacolomy 35400-000 - Ouro Preto - MG $\begin{array}{ll}\text { (31) } 3551-4730 & \text { (31) 3559-7408 }\end{array}$

\section{www.rem.com.br}

